\title{
Meta-analysis of 2-hydroxy-4-methylthio-butanoic acid supplementation on ruminal fermentation, milk production, and nutrient digestibility
}

\author{
X. Feng, ${ }^{*} \dagger^{1}$ R. R. White, $\dagger$ H. A. Tucker, $\ddagger$ and M. D. Hanigan $†$ \\ ${ }^{*}$ College of Life Science and Engineering, Foshan University, Foshan, China 528000 \\ †Department of Dairy Science, Virginia Tech, Blacksburg 24061 \\ ¥Novus International Inc., St. Charles, MO 63304
}

\begin{abstract}
Methionine is considered one of the most important essential AA for milk protein synthesis in dairy cows. Supplementation of unprotected, free Met is nearly $100 \%$ degraded by ruminal microorganisms, which complicates supplementation. 2-Hydroxy-4-methylthiobutanoic acid (HMTBa) can be converted to Met in the body and is used as a Met source in dairy production. However, results of published studies assessing the effects of supplementing Met sources, including HMTBa, on performance variables are inconsistent. A metaanalysis was performed to quantitatively summarize the accumulated results of HMTBa supplementation on animal performance and nutrient digestibility. Data pertaining to HMTBa dose, dietary composition, and major performance variables (rumen volatile fatty acid composition, milk production, nutrient digestibility) were collected from 39 articles containing 169 treatment means. Publications were from scientific journals published from 1970 to 2018; 1 internal report from Novus International Inc. (St. Charles, MO) was also included. The HMTBa effects on response variables were analyzed using linear mixed models with random study effects. Other explanatory variables tested included neutral detergent fiber and crude protein percent as well as days in milk. Results showed that HMTBa supplementation increased blood Met concentration and milk fat yield but had no effect on nutrient digestibility. Key words: 2-hydroxy-4-methylthio-butanoic acid (HMTBa), meta-analysis, digestibility
\end{abstract}

\section{INTRODUCTION}

Methionine is often a limiting AA for milk protein synthesis (Vyas and Erdman, 2009; Patton, 2010). In addition to its role as a substrate for protein synthesis,

Received September 16, 2017.

Accepted April 13, 2018.

${ }^{1}$ Corresponding author: yangxin@vt.edu
Met is a strong regulator of protein synthesis (Appuhamy et al., 2011) and is involved in transsulfuration and methylation reactions (Brosnan and Brosnan, 2006). Balancing rations with supplemental Met to improve the AA profile could allow for reduced dietary $\mathrm{CP}$, maximizing lactation performance, and minimizing $\mathrm{N}$ excretion to the environment.

Free Met in an unprotected form is almost completely degraded by rumen microbes, resulting in minimal or no additional postruminal Met supply. An effective way to increase postruminal Met supply is to feed a Met product that escapes microbial degradation in the rumen. Protection is commonly achieved by chemical modifications or by physically protecting the Met. One example of chemical modification is 2-hydroxy-4-methylthio-butanoic acid (HMTBa), which is a Met analog where the amino group is replaced with a hydroxyl group. The results on whether this modification could effectively protect HMTBa from ruminal degradation are inconsistent. Koenig et al. (1999) reported about $50 \%$ of the HMTBa escaped ruminal degradation and became available for postruminal absorption, whereas Jones et al. (1988) observed 99\% of the HMTBa was altered or degraded by rumen microbes.

Researchers have conducted numerous studies over the years to investigate the effects of HMTBa supplementation on performance of dairy cows, but results have been highly variable. Some studies have reported HMTBa supplementation increased milk fat yield (Polan et al., 1970; Lundquist et al., 1985) and enhanced rumen microbial activity (Holter et al., 1972; Lee et al., 2015). Some studies have also reported no beneficial effects of supplemental HMTBa (Olson and Grubaugh, 1974; Wallenius and Whitchurch, 1974). Because of this disparity in the literature, a need and an opportunity exist to test the effects of supplementing HMTBa across all published studies. The meta-analysis done by Zanton et al. (2014b) included 17 papers on HMTBa supplementation, but only lactation responses to supplemental Met sources were analyzed. Their metaanalysis concluded HMTBa supplementation increases 
milk fat yield by $45 \mathrm{~g} / \mathrm{d}$ and milk protein yield by 13 $\mathrm{g} / \mathrm{d}$, suggesting beneficial effects of supplemental HMTBa. Combining previous work and the previous metaanalysis, these data suggest a potential for HMTBa to affect rumen fermentation. More specifically, with increased ruminal microbial activity from supplemental HMTBa, it is possible HMTBa would increase nutrient digestibility and microbial $\mathrm{N}$ flow. Thus, a more comprehensive meta-analysis is needed to investigate the effects of supplemental HMTBa on rumen fermentation, milk production, and nutrient digestion.

The objective of this work was to use a meta-regression approach to study the effects of HMTBa supplementation. We hypothesized that supplementation of HMTBa would affect ruminal fermentation, milk production, and nutrient digestibility.

\section{MATERIALS AND METHODS}

\section{Data Collection and Preparation}

To accomplish the objective, data were collected from different published articles in the literature (see Appendix Table A1 for list of publications). PubMed, Science Direct, AGRICOLA, and Web of Science databases were searched using the keywords combination from group 1 (methionine, methionine hydroxyl analog or MHA, 2-hydroxy-4-methylthio-butanoic acid or HMTBa or HMB, and ALIMET feed supplement) and group 2 (ruminants, dairy cows, cows, or cattle). Literature cited in these papers was also used to look for papers investigating HMTBa effects. A total of 39 articles reporting results from a total of 169 treatments were collected. Among the 39 articles, 3 reported work conducted with beef cattle breeds and the remainder reported findings from dairy cows. Articles that did not report the inclusion rate of HMTBa were not used. Data on dietary nutrient composition, HMTBa dose, DIM, milk yield, milk composition, ruminal VFA concentration, and blood Met concentration were collected from each article. Milk fat and protein yield were calculated using milk yield and fat or protein content when component yields were not reported. Ruminal VFA were converted to a percentage of total VFA, where total VFA was the sum of acetate, propionate, butyrate, valerate, isobutyrate, and isovalerate if reported. The supplemental amount of commercial HMTBa was converted to a pure HMTBa basis using multipliers of 0.88 and 0.84 for liquid and Ca salt forms of HMTBa, respectively. As a categorical variable, DIM at the beginning of the study was grouped into 4 categories $(0$ $=$ dry period; $1=$ first third of lactation, where DIM is less than $100 \mathrm{~d}$ after calving; $2=$ second third of lactation, where DIM is between 100 and $200 \mathrm{~d}$ after calving; 3 = last third of lactation, where DIM is more than $200 \mathrm{~d}$ after calving).

\section{Model Derivation Procedure}

All statistical analysis were conducted using $\mathrm{R}$ v. 3.1.3 (R Core Team, 2015). The lmerTest package (Kuznetsova et al., 2016) was used to derive linear mixed models with random intercept effects for each study. Independent variables used in the model were HMTBa dose $(\mathrm{g} / \mathrm{d}), \mathrm{CP}$ percent, NDF percent, and DIM category. Initial models generally included all independent variables described above as potential effectors of the response variable. Interactions of HMTBa and each independent variable, as well as quadratic effects of HMTBa, were tested but not significant, and thus were not included in the initial models. Models were derived following the procedure outlined in Roman-Garcia et al. (2016) and White et al. (2016) with minor modification. Briefly, final models were derived using backward elimination of nonsignificant effects, with the parameter possessing the largest $P$-value removed from the model in the subsequent round. The process was repeated until all $P$-values were less than 0.1 . Any remaining parameters with variance inflation factors (VIF) greater than 10 were removed. The VIF is a measure of the severity of multicollinearity reflecting the degree to which parameter estimate variance is inflated due to collinearity and has been used in previous work as a model selection tool (White et al., 2017). A VIF $>10$ is often used to indicate unacceptably high multicollinearity (Roman-Garcia et al., 2016) and is the threshold that we used in the current study.

\section{Evaluating Model Performance}

Overall variance of the predictions was determined by calculation of concordance correlation coefficients (CCC; St-Pierre, 2004)) and mean square error (MSE) as described by Bibby and Toutenburg (1977):

$$
\mathrm{MSE}=\frac{1}{n} \sum_{i=1}^{n}\left(O_{i}-P_{i}\right)^{2}
$$

where $n$ represents the total number of observations, $O_{i}$ the observed value, and $P_{i}$ the predicted value. The MSE was decomposed into error due to random variation, deviation of the regression slope from unity (slope bias), and central bias (mean bias). Root mean square errors (RMSE) were obtained by taking the square root of the MSE. This RMSE was expressed as a proportion 
FENG ET AL.

Table 1. Summary statistics for the data included in the data set

\begin{tabular}{|c|c|c|c|c|c|}
\hline Item & $\mathrm{N}^{1}$ & Mean & Median & Minimum & Maximum \\
\hline Studies & 39 & & & & \\
\hline HMTBa dose ${ }^{2} \mathrm{~g} / \mathrm{d}$ & 169 & 23.1 & 9.81 & 0.00 & 77.4 \\
\hline $\mathrm{DMI}, \mathrm{kg} / \mathrm{d}$ & 148 & 19.4 & 18.9 & 7.50 & 29.8 \\
\hline $\mathrm{BW}, \mathrm{kg}$ & 101 & 598 & 600 & 343 & 778 \\
\hline DIM & 152 & 40.3 & 4.00 & -21 & 300 \\
\hline \multicolumn{6}{|l|}{ Feed composition, \% } \\
\hline $\mathrm{CP}$ & 138 & 15.7 & 15.8 & 7.60 & 20.4 \\
\hline NDF & 72 & 36.8 & 36.1 & 19.0 & 62.1 \\
\hline \multicolumn{6}{|l|}{ Milk production } \\
\hline Milk, $\mathrm{kg} / \mathrm{d}$ & 154 & 28.6 & 27.6 & 5.76 & 45.3 \\
\hline Fat, $\%$ & 152 & 3.53 & 3.57 & 1.69 & 4.57 \\
\hline Fat yield, $\mathrm{kg} / \mathrm{d}$ & 125 & 0.98 & 0.95 & 0.10 & 1.80 \\
\hline Protein, $\%$ & 113 & 3.21 & 3.21 & 2.64 & 3.81 \\
\hline Protein yield, $\mathrm{kg} / \mathrm{d}$ & 90 & 0.93 & 0.91 & 0.18 & 1.41 \\
\hline \multicolumn{6}{|l|}{ Digestibility, \% } \\
\hline DM & 17 & 66.4 & 66.6 & 58.8 & 77.7 \\
\hline $\mathrm{OM}$ & 14 & 63.6 & 65.0 & 49.3 & 77.4 \\
\hline $\mathrm{NDF}$ & 16 & 46.8 & 48.8 & 15.2 & 69.9 \\
\hline $\mathrm{CP}$ & 21 & 66.7 & 66.1 & 58.0 & 80.1 \\
\hline \multicolumn{6}{|l|}{ Rumen VFA, \% } \\
\hline Acetate & 42 & 62.0 & 61.0 & 49.6 & 79.1 \\
\hline Propionate & 42 & 23.7 & 24.0 & 12.5 & 30.3 \\
\hline Butyrate & 42 & 12.6 & 12.3 & 5.20 & 19.2 \\
\hline Valerate & 34 & 1.48 & 1.45 & 0.54 & 2.55 \\
\hline Blood Met, $\mu M$ & 36 & 27.2 & 22.1 & 14.8 & 50.0 \\
\hline
\end{tabular}

${ }^{1} \mathrm{~N}=$ number of treatments.

${ }^{2}$ Mean of 2-hydroxy-4-methylthio-butanoic acid (HMTBa) is not including controls.

of the observed mean to estimate the overall prediction error. Inclusion of the random intercept effects for each study improves the accuracy of the final model and likely results in an error range that reflects biological variation or true response variability. However, when applied on a farm, often a mean bias is associated with model prediction and model results unadjusted for study intercepts can be a more realistic reflection of mean biases that might be expected when applying a model on a farm. This is also supported by the idea that prediction errors in mixed model estimations will be underestimated if uncertainty surrounding the future study effects are not accounted for (Renaudeau et al., 2011). In an effort to show the true response variability and a more conservative estimate of how the model might perform on an individual farm or in a naïve prediction situation, RMSE and CCC were reported with (adjusted) and without study effects (unadjusted). The ratio of between-study variance to total variance was also reported.

\section{RESULTS AND DISCUSSION}

\section{Descriptive Statistics of the Data}

A summary of the descriptive statistics of the data can be found in Table 1. Every variable has a different number of observations according to what was reported in each study. The minima and maxima document the ranges of each variable within the data set. The HMTBa dose ranged from 0 to $77.4 \mathrm{~g} / \mathrm{d}$ with a mean of $23.1 \mathrm{~g} / \mathrm{d}$. The average of supplemental HMTBa as a percent of DMI was 0.15, where the average of DMI was $19.4 \mathrm{~kg} / \mathrm{d}$. The CP and NDF percent ranged from 7.6 to $20.4 \%$ and 19 to $62.1 \%$ of dietary DM, respectively. Blood Met concentrations ranged from 14.8 to $50 \mu M$ with a mean of $27.2 \mu \mathrm{M}$.

\section{Effects of HMTBa Supplementation on Ruminal Fermentation and Nutrient Digestibility}

The final models of ruminal VFA composition (\%) and nutrient digestibility (\%) with HMTBa dose are presented in Table 2. The effects of supplemental HMTBa on ruminal VFA molar proportions were not significant. As would be expected based on a large body of prior literature (Lundquist et al., 1983; Wang et al., 2010), the molar proportion of acetate was significantly affected by the NDF percent in the diet. Increasing CP percent increased molar proportion of valerate according to the current analysis. Supplementation of HMTBa did not affect DM, OM, NDF, or CP digestibility. The models of DM, OM, and NDF are not presented in the table because of no significant predictors $(P<0.1)$ left in the model after the backward elimination. 
Table 2. Effect of 2-hydroxy-4-methylthio-butanoic acid (HMTBa) supplementation on ruminal VFA production (\% basis) and nutrient digestibility (\%)

\begin{tabular}{llccc}
\hline Variable & Predictor $^{1}$ & Estimate & SE & $P$-value \\
\hline Acetate, $\%$ & Intercept & 43.9 & 11.5 & 0.01 \\
& NDFpct & 0.76 & 0.36 & 0.09 \\
Propionate, \% & Intercept & 20.7 & 1.83 & $<0.001$ \\
& DIM1 & 5.61 & 2.23 & 0.04 \\
& DIM2 & 1.83 & 2.29 & 0.45 \\
Valerate, $\%$ & DIM3 & 0.64 & 4.49 & 0.86 \\
& Intercept & 0.09 & 0.59 & 0.88 \\
CP, $\%$ & CPpct & 0.09 & 0.04 & 0.02 \\
& Intercept & 90.5 & 9.02 & 0.0001 \\
& CPpct & -1.45 & 0.57 & 0.047 \\
\hline
\end{tabular}

${ }^{1}$ DIM1 $=$ first third of lactation, where DIM is less than $100 \mathrm{~d}$ after calving; DIM2 = second third of lactation, where DIM is between 100 and $200 \mathrm{~d}$ after calving; DIM3 = last third of lactation, where DIM is more than $200 \mathrm{~d}$ after calving; CPpct $=\%$ of $\mathrm{CP}$ of the diet; NDFpct $=\%$ of $\mathrm{NDF}$ of the diet.

Koenig et al. (2002) observed that, on average, 39.5\% of dosed HMTBa escaped the rumen, with $22 \%$ appearing in the duodenum and $17.6 \%$ apparently absorbed from the omasum. The remaining $60.5 \%$ was largely degraded or used by ruminal microorganisms and, to a lesser extent, absorbed across the ruminal epithelium (McCollum et al., 2000). The HMTBa can be used by rumen microbes to synthesize Met or catabolized to provide sulfur and energy (Belasco, 1980). Noftsger et al. (2003) reported that supplemental Met sources could spare Met precursors, resulting in more efficient protein synthesis or by shifting bacterial species. It has been previously reported that HMTBa supplementation increased microbial protein synthesis, improved carbohydrate digestibility, changed the profile of fermentation products, and increased protozoa numbers (Patton et al., 1970; Gil et al., 1973; Ray et al., 1983); however, we did not observe effects on ruminal fermentation. Due to the low number of observations of microbial $\mathrm{N}$ flow, the effects of HMTBa could not be analyzed.

\section{Effects of HMTBa Supplementation on Production Performance}

Supplementation of HMTBa had no effect on milk yield, fat percent, protein percent, or protein yield, but fat yield increased (Table 3). Zanton et al. (2014b) reported HMTBa supplementation increased milk fat by $5.38 \mathrm{~g} / \mathrm{g}$ of MP Met from HMTBa, whereas in the current study HMTBa supplementation increased fat by $5 \mathrm{~g} / \mathrm{g}$ of MP Met, assuming $60 \%$ of Met from HMTBa degraded in the rumen. The beneficial effects of HMTBa supplementation on milk fat have been well characterized in some studies (Polan et al., 1970; Holter et al., 1972; Wang et al., 2010). Patton et al. (1970) reported HMTBa can stimulate rumen polar

Table 3. Effect of 2-hydroxy-4-methylthio-butanoic acid (HMTBa) supplementation on milk production and blood Met concentration

\begin{tabular}{llccc}
\hline Variable & Predictor $^{1}$ & Estimate & SE & $P$-value \\
\hline Milk, kg/d & Intercept & 28.1 & 2.84 & $<0.001$ \\
& DIM1 & 4.62 & 3.61 & 0.21 \\
DIM2 & -0.62 & 3.76 & 0.87 \\
DIM3 & -7.89 & 4.21 & 0.07 \\
Intercept & 3.34 & 0.35 & $<0.001$ \\
NDFpct & 0.01 & 0.007 & 0.08 \\
& DIM1 & -0.12 & 0.29 & 0.68 \\
DIM2 & -0.27 & 0.28 & 0.37 \\
Fat, kg/d & DIM3 & 0.39 & 0.32 & 0.25 \\
& Intercept & 0.51 & 0.17 & 0.002 \\
Protein, $\%$ & HMTBa dose & 0.002 & 0.0007 & 0.013 \\
& CPpct & 0.03 & 0.01 & 0.0005 \\
Protein, kg/d & Intercept & 3.42 & 0.11 & $<0.001$ \\
& NDFpct & -0.007 & 0.003 & 0.017 \\
& Intercept & 0.38 & 0.59 & 0.52 \\
& CPpct & 0.07 & 0.03 & 0.05 \\
& NDFpct & -0.007 & 0.003 & 0.02 \\
Dlood Met, $\mu M$ & DIM1 & -0.23 & 0.18 & 0.23 \\
& DIM2 & -0.27 & 0.19 & 0.18 \\
& DIM3 & -0.67 & 0.20 & 0.005 \\
& Intercept & 58.4 & 14.3 & 0.001 \\
& HMTBa dose & 0.41 & 0.11 & 0.002 \\
\hline
\end{tabular}

${ }^{1}$ DIM1 $=$ first third of lactation where DIM is less than $100 \mathrm{~d}$ after calving; DIM2 = second third of lactation where DIM is between 100 and $200 \mathrm{~d}$ after calving; DIM3 = last third of lactation where DIM is more than $200 \mathrm{~d}$ after calving; CPpct $=\%$ of $\mathrm{CP}$ of the diet; NDFpct $=\%$ of NDF of the diet. 
lipid formation in vitro and suggested this lipid class increases with protozoa growth. The increased formation of specific biohydrogenation intermediates (e.g., trans-10 C18:1) exerts antilipogenic effects in the mammary gland of ruminants and is considered to attribute the causal mechanism underlying diet-reduced milk fat depression (Shingfield and Griinari, 2007). Baldin et al. (2018) observed that HMTBa decreased the isomers of the alternate pathway of ruminal biohydrogenation (trans-10 C18:1) and increased isomers of the normal pathway of ruminal biohydrogenation (trans-11 C18:1). The supplemental HMTBa may contribute to the increased milk fat yield based on these findings.

One gram of HMTBa increased blood Met concentration by $0.41 \mu M$. Supplemental HMTBa that escapes ruminal degradation is absorbed mostly in the small intestine, is rapidly converted to L-Met, and shows identical metabolism to any other source of L-Met, including intact protein (Huber et al., 1984). This is consistent with previous findings, as Zanton et al. (2014a) reported pulse-dosed intraruminal administration of HMTBa increased serum Met concentrations. Wang et al. (2010) observed that, when diet was supplemented with HMTBa (0.15\% DM basis), plasma concentration was increased $45 \%$ compared with control (29.4 vs. 48 $\mu M)$. With a DMI of $20.7 \mathrm{~kg}$, it was calculated that each gram of HMTBa increased plasma Met by $0.6 \mu M$. Given the observed blood Met concentration response to HMTBa dose, it could be used as a potential indicator of HMTBa bioavailability in dairy cows. A residual plot of blood Met showed no systematic patterns, indicating relatively good fit of the model.

Table 4. Evaluation of models predicting 2-hydroxy-4-methylthiobutanoic acid (HMTBa) responses

\begin{tabular}{lcc}
\hline Item $^{1}$ & Fat, $\mathrm{kg} / \mathrm{d}$ & Blood Met, $\mu M$ \\
\hline $\mathrm{N}$ & 102 & 24 \\
Observed mean & 1.01 & 28.5 \\
Predicted mean & 1.01 & 28.5 \\
RMSE, units & 0.08 & 5.82 \\
Unadjusted RMSE, units & 0.28 & 9.11 \\
RMSE, \% mean & 7.92 & 20.4 \\
Unadjusted RMSE, \% & 25.9 & 32.0 \\
Mean bias, \% MSE & 0.00 & 0.00 \\
Slope bias, \% MSE & 0.88 & 2.86 \\
Residual error, \% MSE & 99.1 & 97.1 \\
CCC & 0.96 & 0.86 \\
Unadjusted CCC & 0.65 & 0.60 \\
$I^{2}$ & 0.74 & 0.46 \\
\hline
\end{tabular}

${ }^{1} \mathrm{~N}$ : indicates number of treatments; RMSE: root mean squared prediction error; CCC: concordance correlation coefficient; MSE: mean squared error; $I^{2}$ : ratio of between study variance to total variance; RMSE and CCC unadjusted for study effects are also reported.

\section{Model Evaluation}

Table 4 lists the fit statistics for the fat yield and blood Met concentration models in which HMTBa were significant. Due to missing values for independent variables, the number of observations used to fit the model ranged from 24 for the blood Met concentration model to 102 for the fat yield model. The observed and predicted means are the same in all cases as would be expected when linear models were fit to the data. Residuals without study effects can better represent error bounds that could be expected in a practical application scenario, but adjusted values can provide better estimates of the true response; residuals are seen in Figure 1 for predicted fat yield and Figure 2 for predicted blood Met. For purposes of discussion, we refer to the adjusted values for linear mixed models. For RMSE, the unadjusted values were all much higher than the adjusted values, as would be expected when study is a significant factor in the model. For CCC, the adjusted values were much higher than unadjusted values. The MSE represents the total variation associated with the predictions, but the value has units that are a square of the predicted values so it is not intuitive to interpret. Simply taking the square root of it yields units that are identical to the predicted value (i.e., RMSE). Comparing the magnitude of RMSE to the observed mean (RMSE as \% of mean) values displays the relative accuracy of the model. When RMSE is expressed as a percentage of the observed mean, it is equivalent to a coefficient of variation, and $10 \%$ is generally a good representation for a biological measurement (Bibby

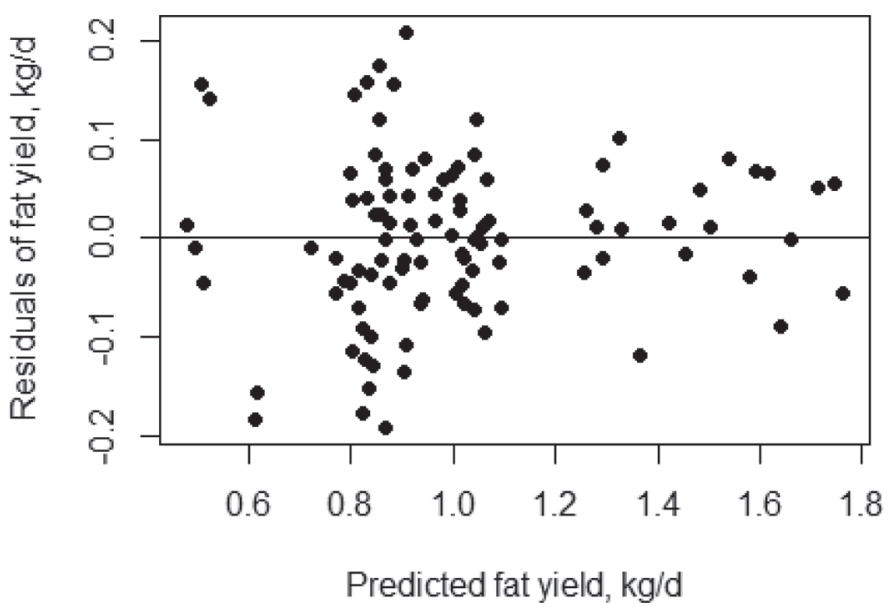

Figure 1. Residual errors for predictions of fat yield versus predicted yield. Fat yield were predicted using the parameters listed in Table 3 , and residuals were calculated as the difference between observe and predicted values. 


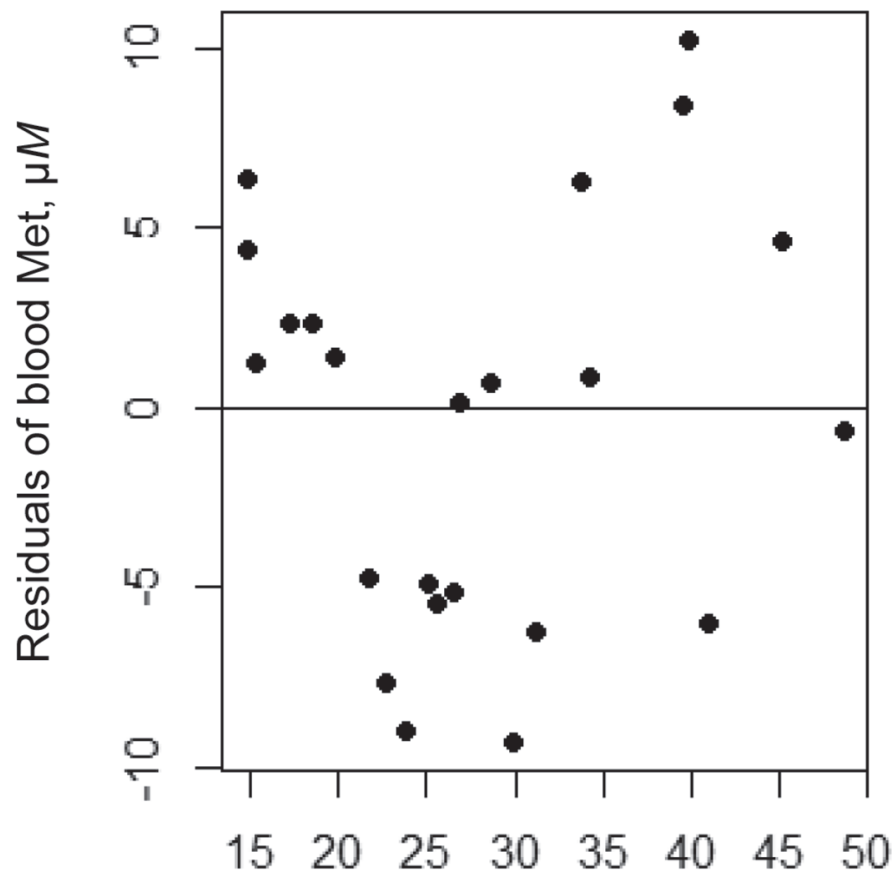

Predicted blood Met, $\mu M$

Figure 2. Residual errors for predictions of blood Met versus predicted concentrations. Blood Met concentrations were predicted using the parameters listed in Table 3, and residuals were calculated as the difference between observed and predicted values.

and Toutenburg, 1977). In our study, the blood Met concentration model had a RMSE of $20.4 \%$, indicating poor fit, which could be due to the low number of available observations. The CCC measures the agreement between observed and predicted values and is somewhat analogous to coefficient of determination. In accordance with the RMSE, the CCC value for blood Met concentration (0.86) was also lower compared with the fat yield models (0.96). By decomposing MSE, we observed that the mean and slope bias were only a small portion, where the residual error is almost $99 \%$ of MSE for fat yield model and $97 \%$ for blood met model, indicating most of the remaining variance is not due to or explained by the model.

\section{CONCLUSIONS}

This meta-analysis evaluated quantitative relationships between HMTBa supplementation and major performance and digestibility variables. Supplementation of HMTBa increased blood Met concentration and milk fat yield. Although HMTBa supplementation increased milk fat yield, further studies are needed to evaluate the mode of action by which this is occurring.
Future independent data can be used to independently evaluate the models derived herein.

\section{ACKNOWLEDGMENTS}

This project was supported by Novus International Inc. (St. Charles, MO).

\section{REFERENCES}

Appuhamy, J. A., J. R. Knapp, O. Becvar, J. Escobar, and M. D. Hanigan. 2011. Effects of jugular-infused lysine, methionine, and branched-chain amino acids on milk protein synthesis in high-producing dairy cows. J. Dairy Sci. 94:1952-1960.

Baldin, M. 2016. Effect of Dietary Interventions on ruminal biohydrogenation and milk fat depression in lactating Holstein cows. $\mathrm{PhD}$ Diss. Department of Animal Sciences, Penn State University, State College.

Baldin, M., G. I. Zanton, and K. J. Harvatine. 2018. Effect of 2-hydroxy-4-(methylthio)butanoate (HMTBa) on risk of biohydrogenation-induced milk fat depression. J. Dairy Sci. 101:376-385.

Belasco, I. J. 1980. Fate of carbon-14 labeled methionine hydroxy analog and methionine in the lactating dairy cow. J. Dairy Sci. 63:775-784.

Bhargava, P. K., D. E. Otterby, J. M. Murphy, and J. D. Donker. 1977. Methionie hydroxyl analog in diets for lactating cows. J. Dairy Sci. 60:1594-1604.

Bibby, J., and H. Toutenburg. 1977. Prediction and Improved Estimation in Linear Models. Wiley, Chichester, UK.

Brosnan, J. T., and M. E. Brosnan. 2006. The sulfur-containing amino acids: an overview. J. Nutr. 136:1636S-1640S.

Chandler, P. T., C. A. Brown, R. P. Johnston, G. K. Macleod, R. D. McCarthy, B. P. Moss, A. H. Rakes, and L. D. Satter. 1976. Protein and methionine hydroxyl analog for lactating cows. J. Dairy Sci. 59:1897-1909.

Chen, Z., G. A. Broderick, N. D. Luchini, B. K. Sloan, and E. Devillard. 2011. Effect of feeding different sources of rumen-protected methionine on milk production and N-utilization in lactating dairy cows. J. Dairy Sci. 94:1978-1988.

Clark, A. K., and A. H. Rakes. 1982. Effect of methionine hydroxyl analog supplementation on dairy cattle hoof growth and composition. J. Dairy Sci. 65:1493-1502.

Clements, A. R. 2015. Effects of supplementing methionine hydroxyl analog on beef cow performance, milk production, and reproduction. MS Thesis. Department of Animal Sciences, University of Illinois at Urbana-Champaign, Urbana.

Gil, L. A., R. L. Shirley, and J. E. Moore. 1973. Effect of methionine hydroxy analog on growth amino acid content, and catabolic products of glucolytic rumen bacteria in vitro. J. Dairy Sci. 56:757-762.

Hansen, W. P., D. E. Otterby, J. G. Linn, and J. D. Donker. 1991. Influence of forage type, ration of forage to concentrate, and methionine hydroxyl analog on performance of dairy cows. J. Dairy Sci. 74:1361-1369.

Higginbotham, G. E., J. D. Schuh, L. Kung, and J. T. Huber. 1987. Palatability of methionine hydroxyl analog or DL-methionine for lactating dairy cows. J. Dairy Sci. 70:630-634.

Holter, J. B., C. W. Kim, and N. F. Colovos. 1972. Methionine hydroxy analog for lactating dairy cows. J. Dairy Sci. 55:460-465.

Huber, J. T., R. S. Emery, W. G. Bergen, J. S. Liesman, L. Kung Jr., K. J. King, R. W. Gardner, and M. Checketts. 1984. Influences of methionine hydroxy analog on milk and milk fat production, blood serum lipids, and plasma amino acids. J. Dairy Sci. 67:2525-2531.

Hutjens, M., and L. H. Schultz. 1971. Additions of soybeans or methionine analog to high concentrate rations for dairy cows. J. Dairy Sci. 54:1637-1644.

Jenkins, C. J. R. 2014. The effects of HMTBa (2-hydroxy-4-methylthiobutanoic acid) supplementation on ruminal microbial crude protein synthesis and community structure in dairy cattle. MS 
Thesis. Animal Science Department, University of Nebraska-Lincoln, Lincoln.

Johnson-VanWieringen, L. M., J. H. Harrison, D. Davidson, M. L. Swift, M. A. G. von Keyserlingk, M. Vazquez-Anon, D. Wright, and W. Chalupa. 2007. Effects of rumen-undegradable protein sources and supplemental 2-hydroxy-4-(methylthio)-butanoic acid and lysine HCL on lactation performance in dairy cows. J. Dairy Sci. 90:5176-5188.

Jones, B. A., O. E. Mohamed, R. W. Prange, and L. D. Satter. 1988. Degradation of methionine hydroxy analog in the rumen of lactating cows. J. Dairy Sci. 71:525-529.

Klangnok, P., P. Lounglawan, and W. Suksombat. 2011. Effects of methionine hydroxyl analog supplementation of dairy cows' diet on milk yield and milk composition. Suranaree J. Sci. Technol. 18:99-108.

Koenig, K. M., L. M. Rode, C. D. Knight, and P. R. McCullough. 1999. Ruminal escape, gastrointestinal absorption, and response of serum methionine to supplementation of liquid methionine hydroxy analog in dairy cows. J. Dairy Sci. 82:355-361.

Koenig, K. M., L. M. Rode, C. D. Knight, and M. Vazquez-Anon 2002. Rumen degradation and availability of various amounts of liquid methionine hydroxy analog in lactating dairy cows. J. Dairy Sci. 85:930-938.

Kuznetsova, A., P. Brockhoff, and R. Christensen. 2016. lmerTest: Tests in Linear Mixed Effects Models. R package version 2.0-30. Accessed Apr. 25, 2017. http://CRAN.R-project.org/package= lmerTest.

Lee, C., J. Oh, A. N. Hristov, K. Harvatine, M. Vazquez-Anon, and G. I. Zanton. 2015. Effect of 2-hydroxy-4-methylthio-butanoic acid on ruminal fermentation, bacterial distribution, digestibility, and performance of lactating dairy cows. J. Dairy Sci. 98:1234-1247.

Lopez, R., G. D. Pulsipher, J. E. Guerra-Liera, S. A. Soto-Navarro, L. A. Balstad, M. K. Petersen, D. V. Dhuyvetter, M. S. Brown, and C. R. Krehbiel. 2016. Effects of fat and/or methionine hydroxy analog added to a molasses-urea-based supplement on ruminal and postruminal digestion and duodenal flow of nutrients in beef steers consuming low-quality lovegrass hay. J. Anim. Sci. 94:2485-2496.

Lundquist, R. G., J. G. Linn, and D. E. Otterby. 1983. Influence of dietary energy and protein on yield and composition of milk from cows fed methionine hydroxy analog. J. Dairy Sci. 66:475-491.

Lundquist, R. G., D. E. Otterby, and J. G. Linn. 1985. Influence of three concentrations of DL-methionine or methionine hydroxy analog on milk yield and milk composition. J. Dairy Sci. 68:33503354 .

Martin, C., C. Mirande, D. P. Morgavi, E. Forano, E. Devillard, and P. Mosoni. 2013. Methionine analogues HMB and HMBi increase the abundance of cellulolytic bacterial representatives in the rumen of cattle with no direct effects on fibre degradation. Anim. Feed Sci. Technol. 182:16-24.

McCollum, M. Q., M. Vazquez-Anon, J. J. Dibner, and K. E. Webb. 2000. Absorption of 2-hydroxy-4-(methylthio)butanoic acid by isolated sheep ruminal and omasal epithelia. J. Anim. Sci. 78:10781083

Noftsger, S. M., N. R. St-Pierre, S. K. Karnati, and J. L. Firkins. 2003 Effects of 2-hydroxy-4-(methylthio) butanoic acid (HMB) on microbial growth in continuous culture. J. Dairy Sci. 86:2629-2636.

Noftsger, S., N. R. St-Pierre, and J. T. Sylvester. 2005. Determination of rumen degradability and ruminal effects of three sources of methionine in lactating cows. J. Dairy Sci. 88:223-237.

Olson, H. H., and W. R. Grubaugh. 1974. Effect of methionine hydroxy analog feeding on yield and composition of bovine milk. J. Dairy Sci. 57:695-697.

Patton, R. A. 2010. Effect of rumen-protected methionine on feed intake, milk production, true milk protein concentration, and true milk protein yield, and the factors that influence these effects: a meta-analysis. J. Dairy Sci. 93:2105-2118.

Patton, R. A., R. D. McCarthy, L. G. Keske, L. C. Griel Jr., and B. R. Baumgardt. 1970. Effect of feeding methionine hydroxy analog on the concentration of protozoa in the rumen of sheep. J. Dairy Sci. 53:933-935.
Phillips, G. J., T. L. Citron, J. S. Sage, K. A. Cummins, M. J. Cecava, and J. P. McNamara. 2003. Adaptation in body muscle and fat in transition dairy cattle fed differing amounts of protein and methionine hydroxyl analog. J. Dairy Sci. 86:3634-3647.

Piepenbrink, M. S., A. L. Marr, M. R. Waldron, W. R. Butler, T. R. Overton, M. Vazquez-Anon, and M. D. Holt. 2004. Feeding 2-hydroxy-4-(methylthio)-butanoic acid to periparturient dairy cows improves milk production but not hepatic metabolism. J. Dairy Sci. 87:1071-1084.

Plank, J. E. 2011. Methionine and Methionine Analog Supplementation: Comparison of Bioavailability In Dairy Cows and Differential Utilization by Rumen Microbes in Batch Culture. MS Thesis. Department of Animal Sciences, The Ohio State University, Columbus.

Polan, C. E., P. T. Chandler, and C. N. Miller. 1970. Methionine hydroxy analog: Varying levels for lactating cows. J. Dairy Sci. 53:607-610.

Ray, S. R., W. J. Croom Jr., A. H. Rakes, A. C. Linnerud, and J. H. Britt. 1983. Effects of methionine hydroxy analog on milk secretion and ruminal and blood variables of dairy cows fed a low fiber diet. J. Dairy Sci. 66:2084-2092.

R Core Team. 2015. R: A Language and Environment for Statistical Computing. Version 3.1.3. R. Foundation for Statistical Computing, Vienna, Austria.

Renaudeau, D., J. L. Gourdine, and N. R. St-Pierre. 2011. A metaanalysis of the effects of high ambient temperature on growth performance of growing-finishing pigs. J. Anim. Sci. 89:2220-2230.

Roman-Garcia, Y., R. R. White, and J. L. Firkins. 2016. Meta-analysis of postruminal microbial nitrogen flows in dairy cattle. I. Derivation of equations. J. Dairy Sci. 99:7918-7931.

Rosser, R. A., C. E. Plan, P. T. Chandler, and T. L. Bibb. 1971. Effects of why components and methionine analog on bovine milk fat production. J. Dairy Sci. 54:1807-1816.

Rulquin, H., B. Graulet, L. Delaby, and J. C. Robert. 2006. Effect of different forms of methionine on lactational performance of dairy cows. J. Dairy Sci. 89:4387-4394.

Shingfield, K. J., and J. M. Griinari. 2007. Role of biohydrogenation intermediates in milk fat depression. Eur. J. Lipid Sci. Technol. 109:799-816.

St-Pierre, N. R. 2004. Validating mathematical models of biological systems: Application of the concordance correlation coefficient. Pages 341-350 in Proceedings of the 4th International Conference on Sensitivity Analysis of Model Output (SAMO 2004) K. M. Hanson and F. M. Hemez, ed. Los Alamos National Laboratory, Santa Fe, NM.

St-Pierre, N. R., and J. T. Sylvester. 2005. Effects of 2-Hydroxy4-(methylthio) butanoic acid (HMB) and its isopropyl ester on milk production and composition by Holstein cows. J. Dairy Sci. 88:2487-2497.

Stokes, M. R., and J. H. Clark. 1981. Performance of lactating dairy cows fed methionine or methionine analog at two concentrations of dietary crude protein. J. Dairy Sci. 64:1686-1694.

Sun, H., Y. Wu, Y. Wang, C. Wang, and J. Liu. 2017. Effects of addition of Aspergillus oryzae culture and 2-hydroxyl-4-(methylthio) butanoic acid on milk performance and rumen fermentation of dairy cows. J. Anim. Sci. 88:602-609.

Tucker, H. A., K. Harvatine, M. Baldin, and M. Vazquez-Anon. 2015. Efficacy of milk based biomarkers to predict increase in microbial protein yield due to HMTBa supplementation. Novus International Report.

Vyas, D., and R. A. Erdman. 2009. Meta-analysis of milk protein yield responses to lysine and methionine supplementation. J. Dairy Sci. 92:5011-5018.

Wallenius, R. W., and R. E. Whitchurch. 1974. Methionine hydroxy analog or sulfate supplementation for high producing dairy cows. J. Dairy Sci. 58:1314-1318.

Wang, C., H. Y. Liu, Y. M. Wang, Z. Q. Yang, J. X. Liu, Y. M. Wu, T. Yan, and H. W. Ye. 2010. Effects of dietary supplementation of methionine and lysine on milk production and nitrogen utilization in dairy cows. J. Dairy Sci. 93:3661-3670. 
White, R. R., Y. Roman-Garcia, and J. L. Firkins. 2016. Meta-analysis of postruminal microbial nitrogen flows in dairy cattle. II. Approaches to and implications of more mechanistic prediction. J. Dairy Sci. 99:7932-7944.

White, R. R., Y. Roman-Garcia, J. L. Firkins, P. Kononoff, M. J. VandeHaar, H. Tran, T. McGill, R. Garnett, and M. D. Hanigan. 2017. Evaluation of the National Research Council (2001) dairy model and derivation of new prediction equations. 2. Rumen degradable and undegradable protein. J. Dairy Sci. 100:3611-3627.

Whiting, F. M., J. W. Stull, and W. H. Brown. 1971. Free amino acid rations in rumen fluid, blood plasma, milk, and feces during me- thionine and methionine hydroxyl analog supplementary feeding. J. Dairy Sci. 55:983-988.

Zanton, G. I., S. E. Bettis, and M. Vazquez-Anon. 2014a. Plasma L-methionine and supplemental L-methionine precursor responses to rumen administration of a rumen protected DL-methionine source or different levels of 2-hydroxy-4-methylthio-butanoic acid. J. Dairy Sci. 97(E-Suppl. 1):755. (Abstr.).

Zanton, G. I., G. R. Bowman, M. Vázquez-Añón, and L. M. Rode. 2014b. Meta-analysis of lactation performance in dairy cows receiving supplemental dietary methionine sources or postruminal infusion of methionine. J. Dairy Sci. 97:7085-7101.

\section{APPENDIX 1}

Table A1. List of the publications used in the analyses

\begin{tabular}{|c|c|}
\hline Citation & Journal, volume, page range \\
\hline Polan et al. (1970) & J. Dairy Sci. 53:607-610 \\
\hline Holter et al. (1972) & J. Dairy Sci. 55:460-465 \\
\hline Hutjens and Schultz (1971) & J. Dairy Sci. 54:1637-1644 \\
\hline Rosser et al. (1971) & J. Dairy Sci. 54:1807-1816 \\
\hline Whiting et al. (1971) & J. Dairy Sci. 55:983-988 \\
\hline Olson and Grubaugh (1974) & J. Dairy Sci. 57:695-697 \\
\hline Wallenius and Whitchurch (1974) & J. Dairy Sci. 58:1314-1319 \\
\hline Chandler et al. (1976) & J. Dairy Sci. 59:1897-1909 \\
\hline Bhargava et al. (1977) & J. Dairy Sci. 60:1594-1604 \\
\hline Stokes and Clark (1981) & J. Dairy Sci. 64:1686-1694 \\
\hline Clark and Rakes (1982) & J. Dairy Sci. 65:1493-1502 \\
\hline Lundquist et al. (1983) & J. Dairy Sci. 66:475-491 \\
\hline Ray et al. (1983) & J. Dairy Sci. 66:2084-2092 \\
\hline Huber et al. (1984) & J. Dairy Sci. $67: 2525-2531$ \\
\hline Lundquist et al. (1985) & J. Dairy Sci. 68:3350-3354 \\
\hline Lundquist et al. (1985) & J. Dairy Sci. 68:3055-3058 \\
\hline Higginbotham et al. (1987) & J. Dairy Sci. 70:630-634 \\
\hline Jones et al. (1988) & J. Dairy Sci. 71:525-529 \\
\hline Hansen et al. (1991) & J. Dairy Sci. 74:1361-1369 \\
\hline Koenig et al. (2002) & J. Dairy Sci. 85:930-938 \\
\hline Phillips et al. (2003) & J. Dairy Sci. 86:3634-3647 \\
\hline Piepenbrink et al. (2004) & J. Dairy Sci. 87:1071-1084 \\
\hline Noftsger et al. (2005) & J. Dairy Sci. 88:223-237 \\
\hline St-Pierre and Sylvester (2005) & J. Dairy Sci. 88:2487-2497 \\
\hline Rulquin et al. (2006) & J. Dairy Sci. 89:4387-4394 \\
\hline Johnson-VanWieringen et al. (2007) & J. Dairy Sci. 90:5176-5188 \\
\hline Wang et al. (2010) & J. Dairy Sci. 93:3661-3670 \\
\hline Chen et al. (2011) & J. Dairy Sci. 94:1978-1988 \\
\hline Klangnok et al. (2011) & Suranaree J. Sci. Technol. 18:99-108 \\
\hline Plank (2011) & Thesis \\
\hline Martin et al. (2013) & Anim. Feed Sci. Tech. 182:16-24 \\
\hline Jenkins (2014) & Thesis \\
\hline Lee et al. (2015) & J. Dairy Sci. 98:1234-1247 \\
\hline Clements (2015) & Thesis \\
\hline Baldin (2016) & Dissertation \\
\hline Lopez et al. (2016) & J. Anim. Sci. 94:2485-2496 \\
\hline Sun et al. (2017) & J. Anim. Sci. 88:602-609 \\
\hline Baldin et al. (2018) & J. Dairy Sci. 101:376-385 \\
\hline Tucker et al. (2015) & Novus International report \\
\hline
\end{tabular}

